\title{
Action Research on: Improving Method of Teaching Weekend Program Students, in Case of Natural Science First Year Students, Bule Hora University
}

\author{
Kasim Rabayo Boru \\ Department of Mathematics, College of Natural and Computational Science, Bule Hora University, Bule Hora, Ethiopia
}

Email address:

kasimjju@gmail.com

\section{To cite this article:}

Kasim Rabayo Boru. Action Research on: Improving Method of Teaching Weekend Program Students, in Case of Natural Science First Year Students, Bule Hora University. Science Journal of Education. Vol. 9, No. 5, 2020, pp. 127-131. doi: 10.11648/j.edu.20200905.11

Received: August 14, 2020; Accepted: August 27, 2020; Published: September 8, 2020

\begin{abstract}
Throughout the world all universities mostly running regular scheme courses like sciences, engineering, medical, law, social, and humanities and so on. When the demand of instructors for all subjects raised, Universities planned and implemented Extension, Weekend Courses specially for Science and Management even all fields of specially in Ethiopia in 1998 the First level universities started (like Addis Ababa, Haramaya, and so on) weekend courses. Secondly most of the instructors, especially Non-Governmental Offices (NGO) they want to achieve their Graduate Courses continue with their normal employing works. Those weekend courses want to improve quality and quantities properly. So that this article wants to prove how do improve teaching methodology for weekend courses, and then, the purpose of weekend program in educational institutes is to promote education for those who cannot learn at regular time. The aim of this study was to identify teaching methodology mostly used by teachers, preferred teaching methodology for students and its effectiveness. Most weekend students have liked to learn by their preference, mainly because of their interactive nature even though the lecture method dominated in class. Significantly, this study provides valuable information about the trends of teaching of weekend class at Bule Hora University that could lay a good base for further investigation. The results and findings can be taken as a base for the concerning bodies to further improve and enhance their curriculum that encompass teaching and learning process, teachers' trainings and assessment in general. I also did three different action for this improvement of teaching methodology, in Natural Science First year students in one class of total number of students twenty one and I have done quantity method like as percentage concept with questioner patterns from students and instructors in Bule Hora University, Bule Hora, Ethiopia.
\end{abstract}

Keywords: Cooperative Learning, Demonstration, Lecture Method, Weekend Program, Student Centered

\section{Introduction}

\subsection{Background of the Study}

The main objective of weekend program in educational institutes is to promote education for those who cannot learn at regular time due to special problems (job, family problems etc). To get the desired goal and satisfy learners, institutes should follow preferable teaching and learning process which may attract to all learners or in which all learners engaged [5] argue that students' learning is enhanced when their interest is stimulated by using different teaching methods during a teaching session. This is because it will satisfy different groups of students. This research is to examine teaching methods mostly used on weekend students, identify preferable teaching methods for weekend students and to recommend teachers and concerning bodies should work to achieve desired goal by using preferable teaching methodologies. This study was conducted on Natural science first year weekend students of Bule Hora University.

\subsection{Statement of Problem}

One of the major concerns in teaching and learning process of governmental and non-governmental educational institutes is the educational strategies adopted in class rooms. The method of teaching and learning in different educational institutions is lecture based [9]. It helps the student's to gather great amount of information on a subject but it does 
not enable them to properly use this information.

In context of Bule Hora University, students mention different factors that discourage students in weekend program. Among these, one is due to lack of internet access on every place. The most popular methodology used in the teaching of weekend program is lecturing which is not participatory and attractive [11]. The lecture method may not provide sufficient opportunity for the adult student to remember and internalize all the ideas presented [3]. Learners also may not get the opportunity to reflect upon the knowledge imparted through lecturing. It is therefore not a good method in facilitating students' thinking and a changing in students' attitudes [8]

The questions here to be answered are:

1) Whether the methodology is attractive and effective enough to attract students or

2) Variety of teaching methodologies should used in the teaching.

In view of the above problem, it has guided us to conduct the present research by investigating the teaching methodologies adopted in the teaching of weekend program.

\subsection{Objectives}

1) To examine the teaching methodologies that are mostly used in weekend program by the teachers

2) Toidentify which methodology is mostly preferred by the students and

3) To find out the level of effectiveness of methodology that attracts students' participation in class room.

\subsection{Research Design}

The design of this study is quantitative which employs a survey questionnaire approach to get information on preferable teaching method which was filled by students. This approach can be defined most simply as a means of gathering information, usually through self-report using questionnaires or interviews surveys are more commonly considered the medium used for data collection [13]. The word survey is often used to describe a method of gathering information from a sample of units in the population that is to be studied [8]

\subsection{Sampling Method}

The groups of students used in this study were Natural science first year weekend students of Bule Hora University. The numbers of students in this group were 21 and all students were taken by the researchers as sample of the study. The questionnaire was the instrument used. It is required to find out the teaching methods predominantly used in class, teaching methods preferred by students.

\subsection{Data Collection Methods}

To conduct this research we used preferable data collection methods. These were different documents and books on related issue from internet, questionnaires filled by students and class observation by teacher. The data collected using different methods were analyzed according to the way they collected. The data analysis has done with quantitative method, like number and percentage [7]. The analyzed data helped us to investigate preferable teaching methods and effectiveness of teaching methods in weekend students of Natural Science first year.

\section{Related Literature Review}

A shift from the traditional to a progressive mode of education had led to an increased interest in learners' individual differences [14]. The new paradigm is student centered, based on inclusiveness, cooperative learning and encouraged diversity. As reported by [12] an increasing amount of research in the past years points out that the interactive process between individual student and the teacher is very important in determining the nature and quality of learning and development that result from instruction. Some researchers have taken the position that it is the teaching method and not the teacher that is the key to the learning of science. It is believed that most effective learning takes place when the interactive process is one that is best suited to the individual students in terms of learning styles. [1] indicated that more attention than ever was being focused on how to meet the challenges of increased diversity in the classroom. They argued that one of the most significant challenges instructors face is to be tolerant and perceptive enough to recognize learning differences among their students. According to [2], the interest which students show in science subjects and the mastery they demonstrate on completion of a course of study depend on the teaching methods. Unfortunately, inspire of the much focus on teaching strategies in science, students' performance in science subjects have continued to record a persistent and depressing downward trend [6] and state out several factors that affect students achievement, these include the students factors, teachers factors, societal factors, governmental infrastructural problem, language problem, instructional strategies employed by the teacher and recently students learning styles.

To overcome these problems, there is need to struggle for a balance of effective teaching methods such as guided inquiry, demonstration and lecture to students' individual learning styles (Active/Reflective, Sensing/ perceptive, Visual/Verbal, and Sequential/Global, etc) [4]. If the balancing is achieved, it is hoped that all students will be taught in a manner they prefer which will lead to an increased comfort level to learn, and high achievement.

\section{Analysis and Interpretation of Data}

In this chapter we presented the analysis of students responses obtained through questionnaire, and result obtained would be presented by table. The data collected from students through questionnaire was analyzed in terms of percentage. The analysis and interpretation was presented as follows.

i. Mostly used types of teaching methodologies (number 
of students $=21$ ).

Table 1. The teaching methodologies that are strongly in use.

\begin{tabular}{|c|c|c|c|c|c|c|}
\hline S. No & Items of questionnaires & Strongly agree & Agree & Neutral & Disagree & Strongly disagree \\
\hline 1 & My teacher provides opportunities for me to act on the subject. & 7 & 2 & - & 7 & 5 \\
\hline 2 & My teacher ask questions on the subject & 8 & 3 & 3 & 2 & 5 \\
\hline 3 & My teacher provides opportunities for me to do individual project. & 2 & 2 & - & 7 & 10 \\
\hline 4 & $\begin{array}{l}\text { My teacher provides opportunities for me to engage in group works and } \\
\text { discussion. }\end{array}$ & 13 & 4 & 2 & 1 & 1 \\
\hline 5 & My teacher brings us out of classroom to learn subjects & - & - & - & - & 21 \\
\hline 6 & My teacher makes me to do library research on subjects. & 1 & 2 & 1 & 2 & 15 \\
\hline 7 & My teacher makes me do internet research on subjects. & 3 & 5 & 2 & 4 & 7 \\
\hline 8 & My teacher encourages student participation in class. & 1 & 1 & - & 7 & 12 \\
\hline 9 & Variety teaching aids were used in the class. & 2 & 1 & 2 & 5 & 11 \\
\hline 10 & My teacher repeats important subject many times. & 3 & 2 & 1 & 5 & 10 \\
\hline 11 & My teacher lectures on the subject/s. & 18 & 1 & - & 1 & 1 \\
\hline 12 & My teacher makes me memorize about past lesson. & 3 & 5 & 1 & 5 & 7 \\
\hline 13 & My teacher gives us homework to do. & 11 & 5 & - & 3 & 2 \\
\hline 14 & My teacher uses demonstration in his/her teaching & - & - & - & 2 & 19 \\
\hline
\end{tabular}

This study has discovered that, the teaching methodologies that are strongly in use by the Bule Hora University weekend teachers are, the methods of lecture $(18,85.71 \%)$, questioning $(8,38 \%)$, discussion $(13,61.9 \%)$, homework $(11,52.38 \%)$. However the findings showed that lecture is the most popular method adopted by the teachers and active learning methodologies as Natural Science instructors ignored methods like demonstration, individual projects etc.
The responses of the students to the question why is mostly used methodology was the lecture method because enables the lecturer to complete the content of course in given time. Regarding this [7], suggested that it could be due to the fact that lecturers had to deal with large classes as well as wide syllabuses for which the lecture method is economical.

ii. The preferred types of teaching methodologies: Preferred Teaching Methodology (Number of students = 21)

Table 2. The preferred types of teaching methodologies in Bule Hora University Weekend Students.

\begin{tabular}{|c|c|c|c|c|c|c|}
\hline S. No & Items of questionnaires & Most preferred & Preferred & Neutral & Less preferred & Non-preferred \\
\hline 1 & Lecture & 3 & 3 & - & 15 & - \\
\hline 2 & Demonstration & 18 & 2 & 1 & - & - \\
\hline 3 & Homework & 16 & 3 & - & 1 & 1 \\
\hline 4 & Question and answers & 2 & 5 & 4 & 8 & 3 \\
\hline 5 & Individual project & 5 & 6 & 1 & 5 & 4 \\
\hline 6 & Group work and discussion & 15 & 3 & - & 2 & 1 \\
\hline 7 & Out of classroom learning & 3 & 4 & 7 & 4 & 4 \\
\hline 9 & Internet research & 3 & 4 & 5 & 5 & 4 \\
\hline 10 & Class participation & 4 & 4 & 5 & 3 & 5 \\
\hline
\end{tabular}

The findings showed that types of teaching methodologies that are mostly preferred by the students, were discussion (number of students $=17,80.95 \%$ ), demonstration (number of students $18,85.71 \%$ ) and home work (number of students $=16$, $76.19 \%$ ). However, the use of discussion (number of students $=17,80.95 \%$ ) and demonstration (number of students $18,85.71 \%$ ) teaching methodologies chosen to be the most preferred teaching methodology by the students. Most of students answered the question reason why is most preferred as follows. It is most preferable because it facilitate better understanding, it gives time to interact with lecturers, students participation through discussions encourage students' preparation before classes, it made learning interesting and the like. Many studies discovered that good teaching methodologies have a great influence on students' emotion and motivation and increasing students' performance in the learning process. So using most preferred teaching methodology can produce better teaching and learning environment between teachers and students and can result in positive effect on students' motivation and achievement.

\section{Action Plan}

Depending on the findings of the research, the researcher has taken different actions depending on the preferred teaching methodologies identified to improve students' learning in Bule Hora University, the case of Natural Science first year weekend students. Therefore, the following strategies were included during the process of implementation.

Table 3. Action Plan.

\begin{tabular}{llll}
\hline S. No & Action to taken & Methods & Date of an action \\
\hline \multirow{2}{*}{ Lecture for 2 continues hours } & $\begin{array}{l}\text { 1. Teach without any students' task for minutes. } \\
\text { 2. Ask questions at the middle of the session. }\end{array}$ & 24/01/2012 E. C \\
\hline
\end{tabular}




\begin{tabular}{|c|c|c|c|}
\hline S. No & Action to taken & Methods & Date of an action \\
\hline 2 & $\begin{array}{l}\text { Session for } 2 \text { hours using } \\
\text { preferred teaching } \\
\text { methodologies (group } \\
\text { discussion and demonstration) }\end{array}$ & $\begin{array}{l}\text { 3. Again continue lecturing until the session ends. } \\
\text { 4. Observe students' feeling. } \\
\text { 5. Ask question regarding the session to know the effectiveness of teaching method } \\
\text { and assessment taken. } \\
\text { 1. Introduce them about the topic for minutes. } \\
\text { 2. Give them an exercise to discuss in group and facilitate the discussion. } \\
\text { 3. Allow them to present their work. } \\
\text { 4. Allow them to demonstrate their work on logarithm and observe their performance. } \\
\text { 5. Summarize the session }\end{array}$ & 25/01/2012 E. C \\
\hline
\end{tabular}

\subsection{Action Implementation}

\subsubsection{Implementation of First Action}

The researchers / two observed and one taught for two hours as planned above. As researchers observed, for first a few minute students were active, take notes from the board, answer questions and ask questions. At the middle of the session the students' feeling was changed. Some of them get tired; others fell sleeping, and almost all of them waiting the time on which the teachers will leave the class even they showed some actions that describe their feeling which made the teacher to stop the class unintentionally. At the end of the session teacher asked question on topic of the session, few students had reacted to teacher and rest had kept silent.

\subsubsection{Implementation of Second Action}

The researcher introduced overview of the session and gave short notes regarding the topic within the first few minutes. Here all students were active. After couple of minutes, the researcher gave an exercise to solve in group. As researcher observed all students were engaged in discussion and solving a problem and presented their work. After this they ordered by the researcher to demonstrate on logarithm for minutes. All students participated in demonstration and unknowingly the time was up. This shows the session was very interesting.

\subsection{Action Evaluation}

The researcher used three different teaching methodologies. The first and the most popular one lecture methodology on the first day and the most preferred teaching methodologies by students on the second day. The researchers observed the great difference between two different sessions. The students' performance in two sessions was explained above. In view of this, we observed that teaching methodologies have a great role in students' performance and achievement. Having this in mind, we suggested that teaching methodologies should be varied even in the same session. So that concerning bodies and every teacher should responsible to conduct action research not only higher diploma program candidates but also others too.

\section{Conclusion and Recommendation}

\subsection{Conclusion}

The aim of this study was to identify teaching methodology mostly used by teachers, preferred teaching methodology for students and its effectiveness. Most weekend students have liked to learn by their preference, mainly because of their interactive nature even though the lecture method dominated in class. Significantly, this study provides valuable information about the trends of teaching of weekend class at Bule Hora University that could lay a good base for further investigation. The results and findings can be taken as a base for the concerning bodies to further improve and enhance their curriculum that encompass teaching and learning process, teachers' trainings and assessment in general.

\subsection{Recommendation}

Since the lecture method is traditional in nature has proven to be the most popular methodology employed by the teachers. [12], the lecture method is the most popular method used in adult education and does not stimulate much, especially when no allowance is made for discussion after the lecture session; it is by no means a cheap method as is often perceived. I t should be modified and varied. Demonstration is among the most preferred teaching methodology by students. Considering this we recommend the followings.

1) The curriculum development committee, in Bule Hora University should design the way in which teachers to be aware of teaching methodologies.

2) Teachers of Bule University especially teachers who had no pedagogical background should be trained. Because training is essential to ensure that teachers are exposed to different teaching methodologies and therefore make teaching and learning process of weekend as well as regular program effective. Again it is a concern for this Quality Assurance office is stakeholders.

3) Activities and assessments by teachers should be in simple and attractive way so that the students can understand the main objectives of the subject and can apply in real life. This can be done by using well structured session plan, variety of learning styles effectively and using appropriate assessment methods for planned tasks depending on students' preference. [5] Stated that student learning is enhanced when their interest is encouraged by using different teaching methods during a teaching session. This is because it will satisfy different groups of students. According to [12], a combination of teaching methods enhances student learning instead of depending on just one or two.

4) The weekend students who are part time learners that 
mean they have limited time. Considering this teachers have to prepare or provide self study materials before and after the session.

5) Further researches should have done to examine the effectiveness of variety of teaching methodologies. Quality Assurance office should also look into related activities that will increase students' participation in teaching and learning process.

6) Lastly we want so say teaching learning process should attractive, participatory and learner-centered. [12], suggest that adult teaching should be learner-centered rather than teacher-centered. The teacher should be a facilitator and one of the resources among several. Both teacher and learner must work with partnership. Finally, methods of learning must be mainly self-directed and rely mostly on the learner's experience.

\section{Next Step}

In this study we identified that the teaching methodologies that mostly used in weekend education, which teaching methodologies are preferable and proved that the effectiveness of preferred teaching methodologies. However as we have discussed under limitation of the study that the study was conducted on only one section (information technology first year) within short period of time. As result it may not provide standard solution. So we cannot conclude that the study is enough to all students of different groups of different departments because students' preference in different groups may vary. So the study would be continued on different groups to investigate most used teaching methodologies, preferable teaching methodologies and their effectiveness.

\section{Acknowledgements}

The authors wish to acknowledge the authors for providing a published different Article review publication to the first author during 2000s to carry out this Article at Bule Hora University, Oromia regional state, Southern Ethiopia. The critical review and comments offered by Mr. Million Chimdessa and Mr. Kumera Takele were acknowledged. The assistance given from by Prof. Abdulkader Naina Mohamad and Dr. Fufa Esayas to collect the literature from different source is acknowledged.

\section{References}

[1] Anderson, J. A. \& Adams, M. (1992). "Acknowledging the Learning styles of Diverse Stretch Population: Implication for Instructional Design.” In L. L. Border \& N. Van. Chism (Eds) New Jossey-Bass Publishers Inc.

[2] Archibong, A. U, (1999). "The Relative Effectiveness of the Activity Based Approach and Lecture Method on the Cognitive Achievement of Integrated Science Students." Journal of Science Teachers Association of Nigeria (STAN) 32 pp.37-42.
[3] Badu-Nyarko, S., and B. Torto. "Teaching methods preferred by part time tertiary students in Ghana." International Journal Humanities and Social Science 4.1 (2014): 226-233.

[4] Felder, R. M (2002). "Reaching the Second Tier Learning and Teaching Styles in Colleges Science Education" in Journal of College Science Teaching, 23 (2) 286-290.

[5] Fry, J., Medsker, K. \& Bonner, D. (1996). “Teaching Methods and Strategies, ” John Willeis, Vol. 34, pp: 231-248

[6] Inyang, N. E. U. (1993).”Learning Theories: Implications for Science Teaching in Eshiet," I. T (Ed) Methodology of Science Teaching pp. 15-18.

[7] Jansen, Harrie. "The logic of qualitative survey research and its position in the field of social research methods." Forum Qualitative Sozialforschung/Forum: Qualitative Social Research. Vol. 11. No. 2. 2010.

[8] Jarvis, P. (1995). “Adults and Continuing Education. Theory and Practice" Stanford Educational Press, Waterloo, Canada

[9] Kaddoura MA. Critical Thinking Skills of Nursing Students in Lecture-Based Teaching and Case-Based Learning. International Journal for the Scholarship of Teaching and Learning. 2011 Jul; 5 (2):n2.

[10] Matthew Steven Haas and Travis W. Twiford, Chair: "The Influence of Teaching Methods on Student Achievement on Virginia's End of Course Standards of Learning Test for Algebra I" Inter Science, Newyork.

[11] Mukherjee, Neela. Participatory learning and action: With 100 field methods. No. 4. Concept Publishing Company, 2002.

[12] Stephens, M. D. (1989). "Teaching Methods for Adults", Open University, UK.

[13] Weigold, A., Weigold, I. K., \& Russell, E. J. (2013). Examination of the equivalence of self-report survey-based paper-and-pencil and internet data collection methods. Psychological methods, 18 (1), 53.

[14] Zywno, Malgorzata S., and Judith K. Waalen. "The effect of individual learning styles on student outcomes in technologyenabled education." Global J. of Engng. Educ 6.1 (2002): 35-44.

[15] Zywno, M. S. (2002). "Effect of Individual Learning Styles on Students Outcome in Technology-enable Education" Global Journal of Engineering Education 6 (1) pp 240-249.

\section{Biography}

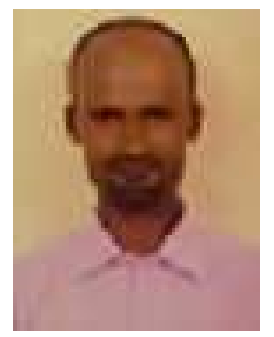

Mr. Kasim Rabayo Boru was graduate by Masters of Science in Mathematics (Differential Equation) from Adama Science and Technology University in March 5, 2015. And employed at Bule Hora University as a lecturer and still serving as instructor in Department of Mathematics. Recently the author continues his work as Head of the

Department of Mathematics in Bule Hora University, Ethiopia. 